\title{
Sensorineural Hearing Affection In Sickle Cell Disease Patients With Chronic Renal Failure Under Dialysis
}

\author{
Saeed Abdelwhab Saeed MD*, Magdy M El Sharkawy MD*, \\ Fedaey M. Abbass, ${ }^{* *}$ M N M R Farahat MD*** \\ Waleed F Ezzat MD ${ }^{* * * *}$
}

\begin{abstract}
* Lecturer of internal med \& nephrology Ain-Shams university, ** Fellow of nepnrology , Ahamed Maher Teaching Hospital ,***assistant professor Of internal med \&immunology Al-Azhar university, **** lecturer of E.N.T. Ain shams university.
\end{abstract}

\begin{abstract}
:
Objective: to study the problem of hearing loss in patients of chronic renal failure on regular haemodialysis and The factors which affect it. And to study the effect of sickle cell disease on hearing loss. we studied hearing loss in dialysis patients, sickle cell disease patients and patients of sickle cell disease with chronic renal failure under dialysis compared to normal control subjects.
\end{abstract}

Design: 83 patients are classified into four groups. group I include sickle cell disease patients with chronic renal failure on regular haemodialysis (18 patients), group II include patients with chronic renal failure on regular haemodialysis (25 patients),group III Include patients with sickle cell disease (20 patients) and group IV include the normal control subjects(20 subjects) .

All groups are subjected to full history, thorough clinical examination including neurological and ENT examination, investigations includes $\mathrm{Hb}$, s. creatinine, s.albumen, s.calcium and calculation of $\mathrm{kt} / \mathrm{v}$ for dialysis patients. Full audiological assessment, using the 46-GSI audiometer was done for all groups with special concentration at frequency of 1,2 and $4 \mathrm{KHZ}$.

Results: hearing loss was found in patients with chronic renal failure more than normal control. Patient with sickle cell disease have hearing disorders significantly higher than normal controls at frequency of $4 \mathrm{KHZ}$ only. Patients with chronic renal failure and sickle cell disease have significantly.

Marked degree of SNHL than those with SCD only. Hearing loss in patients with $\mathrm{SCD}$ correlates with $\mathrm{Hb}$ level $(\mathrm{r}=.317, \mathrm{p}=0.003)$. the degree of hearing affection in patients with chronic renal failure with or without SCD correlate with duration of dialysis , presence of peripheral neuropathy, s. calcium level, efficiency of dialysis marked by kt/v.

Conclusion and recommendation: hearing disorder is common in patients with chronic renal failure under regular haemodialysis and it increase with duration of dialysis it should be suspected if there is Peripheral neuropathy. It can be reduced with efficient dialysis, correction of anemia, adjustment of calcium level. Patients with SCD suffer also some degree of hearing loss especially at higher frequency and this degree of hearing loss 
increase with the degree of anemia precaution to prevent hemolytic crisis and its early treatment is the only way to decrease the progression of SNHL.

\section{Introduction:}

Patients with sickle cell disease are common victims of recurrent attacks of hemolytic and thrombotic crises, these crises are well documented to impair the hearing thresholds of these patients during their crisis attacks, but most of these cases recover most of their hearing abilities within two weeks after recovery, but with long term sensorineural hearing loss (SNHL) over the years ${ }^{1-5}$. Renal failure too has been documented to cause certain degrees of SNHL as a result of the metabolic alterations ${ }^{6,7}$, and the process of dialysis was proposed to be an additional contributing factor for the hearing loss although disputed by many studies ${ }^{8}$. The combination of both diseases and the effect on hearing has not been widely studied due to the relative rarity of surviving patients with sickle cell disease to the age that they actually develop renal failure that necessitates dialysis. Based on these facts, we decided to study the pattern and severity of SNHL in the patients available in a renal failure dialysis center, comparing those with sickle cell disease to those without the disease. We also compared them the former group with sickle cell disease patients without renal failure and normal individuals.

\section{Patients And Methods:}

The study included 83 patients divided into the following groups;

- Group I; Patients with both renal failure under dialysis and with sickle cell disease (18 patients).
- Group II; Patients with renal failure only, and under dialysis (25 patients).

- Group III; Patients with sickle cell disease only (20 patients).

- Group IV; Normal persons (20 persons).

All study groups' age ranges were from 13 to $58 \mathrm{yr}$, so the control group patients were chosen in the same range.

Inclusion criteria for a patient to be termed a sickle cell disease patient were;

1. Positive family history of sickle cell disease.

2. Positive documented history of at least 3 attacks of hemolytic crises within the past 10 years necessitating hospital admission.

3. Hemoglobin $(\mathrm{Hb})$ electroph -oresis showing high levels of $\mathrm{HbS}$ $(>60 \%)$, and low levels of $\mathrm{HbA}_{1}$ $(<40 \%)$, with or without other $\mathrm{Hb}$ types.

Inclusion criteria for a patient to be termed a renal failure patient were;

1. Creatinine clearance less than 20 $\mathrm{ml} / \mathrm{min}$.

2. Patients being diagnosed as renal failure needing dialysis for at least 5 years.

3. Patients under three sessions of dialysis per week, each session 4 hours at least.

\section{Inclusion criteria for a normal patient} were:

1. Free from any chronic disease as diabetes, hypertension, renal 
impairment, rheumatoid diseases, etc.

2. Had no history of previous hearing trouble, or ear diseases or surgery.

3. Had absolutely no history of ototoxic drug administration.

4. Age from 13-58 yr.

\section{All patients were subjected to the following;}

- Full history taking including age ,sex, duration of dialysis, frequency of dialysis, and history of any ear troubles other than diminution of hearing, chronic diseases, renal history, to categorize or eliminate the patient from the study groups.

- Complete clinical exami -nation including neurolo -gical examination include -ing examination for perip -heral neuropathy.

- Thorough otologic examination, including ympanometry, to exclude middle ear diseases.

- Full audiological assess -ment, using the 46-GSI udiometer, with special concentration on the 1 $\mathrm{kHz}, 2 \mathrm{kHz}$, and $4 \mathrm{kHz}$ frequencies.

- Biochemical investigations including Serum creatini -ne to evaluate renal funct -ion, serum calcium, serum albumen.

- Hemoglobin value, to exclude undiagnosed hem oglobinnopathies in cases considered non-sickle cell disease patients, and as a step in the work up of sickle cell disease patients.

- Calculation of $\mathrm{kt} / \mathrm{v}$ for dialysis patients.
Additional tests were done to specific study groups as follows;

- Creatinine clearance, and plasma urea tests for groups I and II.

- Hemoglobin electrophoresis for groups I and III.

\section{Statistical Analysis}

After verifying the condition of each patient and properly categorizing them, the results of the audiometric testing was tabulated and analyzed using the (t) test comparing the thresholds of hearing of each frequency and the mean of the sum of frequencies between the different study groups.

The results of the audiological testing are shown in tables 1-4, and the means and standard deviations and the mean of the sums were shown in tables 5-8

\section{Results}

group I includes 18 patients 8 males and 10 females with mean age of $35.5 y$ r.group II includes 25 patients 10 males and10 females with mean age 31.8yr.group III includes20 patients with 11 males and 9 females and a mean age of 37.5yr.while group IVincludes20 patients with mean age36.2 yr.with12 males and 8 females.

Comparing group I and II showed that There is significant difference in $\mathrm{Hb}$ level $(p=.029)$. No significant difference was found in other parameters.

Comparing group I and III showed a highly significant difference in s. albumen (p <0.001), peripheral neuropathy $(\mathrm{p}<0.001)$.

Comparing group I and IV showed that there is a highly significant difference in the factors related to renal failure i.e. creatinine, albumen, $\mathrm{Hb}$, peripheral neuropathy. 
And s. calcium. Similar results are obtained when comparing group II and IV.

Comparing group III and IV showed that there is a highly significant difference in $\mathrm{Hb}$ level $(\mathrm{p}<0.001)$.

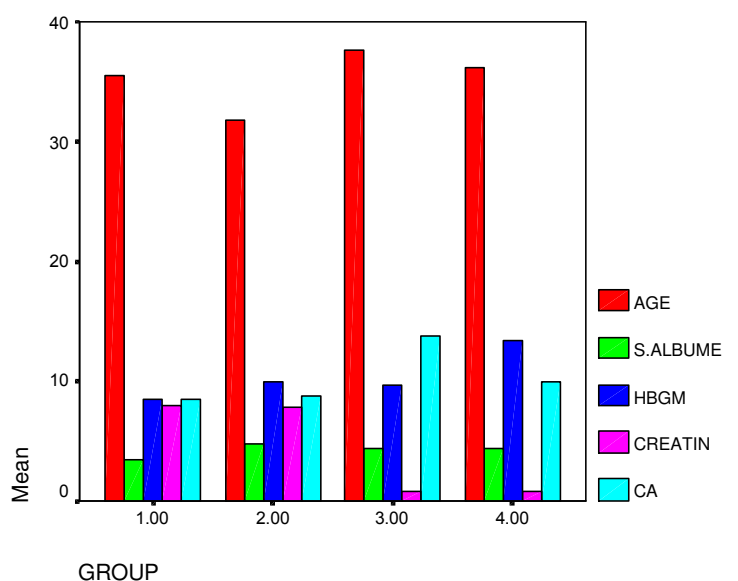

Figure 1 means of variables in different groups

\section{Comparison between}

different groups as regard hearing threshold at different frequencies showed that at $\mathrm{kHz}$ threshold the following was found comparing the different groups with each other;

- Comparing group I and II, showed no I.significant difference statistically.

- Comparing group I and III showed a highly significant difference statistically.

- Comparing group I and IV showed a highly significant difference statistically.

- Comparing group II and III showed a highly significant difference statistically.

- Comparing group II and IV showed a highly significant difference statistically.
- Comparing group III and IV showed no significant difference statistically.

») In the $2 \mathrm{kHz}$ threshold the following was found comparing the different groups with each other;

- Comparing group I and II, showed no significant difference statistically.

- Comparing group I and III showed a significant difference statistically.

- Comparing group I and IV showed a highly significant difference statistically.

- Comparing group II and III showed a significant difference statistically.

- Comparing group II and IV showed a highly significant difference statistically.

- Comparing group III and IV showed no significant difference statistically.

» In the $4 \mathrm{kHz}$ threshold the following was found comparing the different groups with each other;

- Comparing group I and II, showed no significant difference statistically.

- Comparing group I and III showed a highly significant difference statistically.

- Comparing group I and IV showed a highly significant difference statistically.

- Comparing group II and III showed a highly significant difference statistically.

- Comparing group II and IV showed a highly significant difference statistically. 
- Comparing group III and IV showed a significant difference statistically.

» In the sum of mean of the three tested frequencies, the following was found comparing the different groups with each other;

- Comparing group I and II, showed no significant difference statistically.

- Comparing group I and III showed a highly significant difference statistically.

- Comparing group I and IV showed a highly significant difference statistically.

- Comparing group II and III showed a highly significant difference statistically.

- Comparing group II and IV showed a highly significant difference statistically.

- Comparing group III and IV showed no significant difference statistically.

Correlation study showed that hearing threshold at $1,2 \& 4 \mathrm{kHz}$ in dialysis patients correlate with $\mathrm{kt} / \mathrm{v}$ Table 1: The audiological thresholds of (Group I) patients in dB.

\begin{tabular}{|c|c|c|c|}
\hline Patient no. & $1 \mathrm{kHz}$ freq & $2 \mathrm{kHz}$ freq & $25 \mathrm{kHz} f \mathrm{feq}$ \\
\hline 1 & 20 & 25 & 30 \\
\hline 2 & 20 & 20 & 40 \\
\hline 3 & 15 & 15 & 30 \\
\hline 4 & 15 & 15 & 15 \\
\hline 5 & 10 & 15 & 25 \\
\hline 6 & 15 & 25 & 40 \\
\hline 7 & 20 & 35 & 45 \\
\hline 8 & 25 & 15 & 20 \\
\hline 9 & 10 & 10 & 20 \\
\hline 10 & 10 & 10 & 20 \\
\hline 11 & 15 & 20 & 30 \\
\hline 12 & 15 & 15 & 25 \\
\hline 13 & 20 & 25 & 35 \\
\hline 14 & 20 & 20 & 30 \\
\hline 15 & 20 & 30 & 50 \\
\hline 16 & 25 & 35 & 45 \\
\hline
\end{tabular}

$(\mathrm{p}<0.001)$ also with s. calcium $(\mathrm{p}<0.001) \quad$ and

presence of peripheral neuropathy $(\mathrm{p}<0.001)$. While duration of dialysis correlates with hearing threshold at $2 \& 4$ $\mathrm{kHz}(\mathrm{p}<0.001)$. Peripheral neuropathy is found to correlate with duration of dialysis, kt/v and hearing threshold at 1, 2, $4 \mathrm{kHz}$ all in a highly significant degree. $\mathrm{Hb}$ is found to correlate negatively with with hearing threshold at $1 \mathrm{KHZ}(\mathrm{p}<0.05)$.

Figure (2) mean of hearing threshold at different frequencies of the 4 groups.

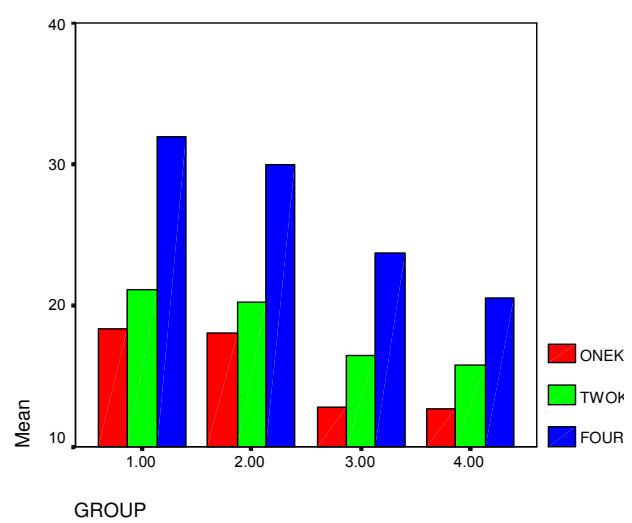
hearing threshold at4 KHZ $(\mathrm{p}<0.001)$ and 
Table 2: The audiological results of (Group II patients) in $\mathrm{dB}$.

\begin{tabular}{|c|c|c|c|}
\hline Patient no. & $1 \mathrm{kHz}$ freq & $2 \mathrm{kHz}$ freq & $4 \mathrm{kHz}$ freq \\
\hline 1 & 10 & 15 & 20 \\
\hline 2 & 10 & 20 & 25 \\
\hline 3 & 15 & 15 & 20 \\
\hline 4 & 15 & 20 & 30 \\
\hline 5 & 20 & 20 & 30 \\
\hline 6 & 20 & 25 & 40 \\
\hline 7 & 20 & 20 & 35 \\
\hline 8 & 25 & 20 & 35 \\
\hline 9 & 20 & 25 & 30 \\
\hline 10 & 25 & 25 & 25 \\
\hline 11 & 20 & 20 & 30 \\
\hline 12 & 15 & 15 & 25 \\
\hline 13 & 10 & 10 & 20 \\
\hline 14 & 15 & 15 & 25 \\
\hline 15 & 10 & 20 & 25 \\
\hline 16 & 20 & 25 & 35 \\
\hline 17 & 25 & 30 & 40 \\
\hline 18 & 15 & 15 & 20 \\
\hline 19 & 20 & 15 & 25 \\
\hline 20 & 20 & 25 & 35 \\
\hline 21 & 20 & 20 & 40 \\
\hline 22 & 25 & 25 & 45 \\
\hline 23 & 20 & 25 & 35 \\
\hline 24 & 25 & 25 & 30 \\
\hline 25 & 10 & 15 & 25 \\
\hline
\end{tabular}

Table 3: The audiological results of (Group III patients) in dB.

\begin{tabular}{|c|c|c|c|}
\hline Patient no. & $1 \mathrm{kHz}$ freq & $2 \mathrm{kHz}$ freq & $4 \mathrm{kHz}$ freq \\
\hline 1 & 10 & 10 & 25 \\
\hline 2 & 20 & 15 & 25 \\
\hline 3 & 10 & 10 & 20 \\
\hline 4 & 15 & 10 & 15 \\
\hline 5 & 10 & 10 & 15 \\
\hline 6 & 10 & 10 & 20 \\
\hline 7 & 10 & 15 & 15 \\
\hline 8 & 15 & 20 & 25 \\
\hline 9 & 15 & 25 & 30 \\
\hline 10 & 15 & 35 & 30 \\
\hline 11 & 20 & 25 & 35 \\
\hline 12 & 15 & 20 & 35 \\
\hline 13 & 15 & 15 & 20 \\
\hline 14 & 10 & 10 & 20 \\
\hline 15 & 5 & 15 & 30 \\
\hline 16 & 10 & 20 & 35 \\
\hline 17 & 10 & 10 & 25 \\
\hline 19 & 15 & 20 & \\
\hline
\end{tabular}


Table 4: The audiological results of (Group IV patients)

\begin{tabular}{|c|c|c|c|}
\hline Patient no. & $1 \mathrm{kHz}$ freq & $2 \mathrm{kHz}$ freq & $4 \mathrm{kHz}$ freq \\
\hline 1 & 10 & 10 & 15 \\
\hline 2 & 15 & 10 & 20 \\
\hline 3 & 15 & 15 & 20 \\
\hline 4 & 10 & 10 & 15 \\
\hline 5 & 15 & 10 & 20 \\
\hline 6 & 10 & 10 & 15 \\
\hline 7 & 10 & 10 & 15 \\
\hline 8 & 15 & 15 & 20 \\
\hline 9 & 20 & 20 & 25 \\
\hline 10 & 15 & 15 & 20 \\
\hline 11 & 10 & 20 & 25 \\
\hline 12 & 10 & 20 & 30 \\
\hline 13 & 15 & 20 & 20 \\
\hline 14 & 15 & 15 & 20 \\
\hline 15 & 10 & 20 & 25 \\
\hline 16 & 15 & 20 & 20 \\
\hline 17 & 15 & 20 & 25 \\
\hline 18 & 15 & 20 & 20 \\
\hline 19 & 10 & 20 & 25 \\
\hline 20 & 10 & 15 & 15 \\
\hline
\end{tabular}

Table 5: Results of statistical analysis of the study groups. (S.D. = standard deviation)

\begin{tabular}{|c|c|c|}
\hline Frequency & Mean & S.D. \\
\hline \multicolumn{3}{|c|}{ GROUP I (18 patients) } \\
\hline $1000 \mathrm{~Hz}$ & 18.33 & 5.6 \\
\hline $2000 \mathrm{~Hz}$ & 21.38 & 8.1 \\
\hline $4000 \mathrm{~Hz}$ & 31.94 & 10.8 \\
\hline Sum of means & 23.88 & 7.8 \\
\hline \multicolumn{3}{|c|}{ GROUP II (25 patients) } \\
\hline $1000 \mathrm{~Hz}$ & 18.00 & 5.2 \\
\hline $2000 \mathrm{~Hz}$ & 20.20 & 4.8 \\
\hline $4000 \mathrm{~Hz}$ & 29.80 & 7.1 \\
\hline Sum of means & 22.67 & 5.1 \\
\hline \multicolumn{3}{|c|}{ GROUP III (20 patients) } \\
\hline $1000 \mathrm{~Hz}$ & 12.75 & 3.7 \\
\hline $2000 \mathrm{~Hz}$ & 16.50 & 7.0 \\
\hline $4000 \mathrm{~Hz}$ & 23.75 & 7.5 \\
\hline Sum of means & 17.66 & 4.9 \\
\hline \multicolumn{3}{|c|}{ GROUP IV (20 patients) } \\
\hline $1000 \mathrm{~Hz}$ & 13.00 & 2.9 \\
\hline $2000 \mathrm{~Hz}$ & 15.7 & 4.3 \\
\hline $4000 \mathrm{~Hz}$ & 20.5 & 4.2 \\
\hline Sum of means & 16.4 & 3.0 \\
\hline
\end{tabular}




\section{Discussion}

Homozygous cases of sickle cell disease were previously considered "early fatalities", this was in part very true due to the severity of the disease and frequency of occurrence of fatal complications, but with recent advances in medicine, a definite cure can be offered to the patient in the form of stem cell transplant ${ }^{9}$. Although this fact is true, it is rarely needed following the precautions of proper prophylaxis from conditions precipitating attacks of sickle crisis, and early treatment of the crisis if it occurs. Also proper genetic counseling has played a role in reduction of the disease severity and number of cases.

The geographical distribution of the disease variants varies from one source to the other, but in the Middle East, and specifically in the Arabian semi-island, the disease takes a specific pattern ${ }^{3}$. In the full blown case there is a very low percentage of $\mathrm{HbA}_{1}$ which may reach zero, with very high levels of $\mathrm{HbS}$, and the remaining usually $\mathrm{HbF}$. This relative high level of $\mathrm{HbF}$ (higher than the described $15 \%$ maximum in literature) with the specific property of very high affinity to oxygen ameliorates the condition greatly, so that the patient may have $\mathrm{Hb}$ levels as low as $6 \mathrm{gm} / \mathrm{dl}$ and still live a more or less symptom free life ${ }^{9}$, and is not considered

to be anemic. The amelioration in the clinical picture of the disease with advances in treatment lines has build up a relatively older aged population of sickle cell disease patients, thus making these patients liable to chronic diseases, including renal failure.

The concept that inner ear cells are sensitive to several metabolic and hormonal disorders is a well studied issue. But, the relationship between chronic renal failure and sensorineural hearing loss is still a debatable issue by the scientific community ${ }^{9}$

The chronic effects of renal failure on hearing have previously been studied 6,7 and it has been shown that there is an increase in the hearing thresholds, especially in the higher frequencies, in these patients. Studies have also failed to demonstrate any long term affection on hearing by the process of dialysis itself ${ }^{8}$. sensorineural hearing loss in these patients may be attributed to the preexisting renal disease ${ }^{10}$ Other investigators found that hearing loss seemed to be affected by the method of management of the renal insufficiency (more in the haemodialysis group than in the peritoneal dialysis group). Although they found no significant changes in audiometric findings before and after haemodialysis $^{12-13}$.

Some investigators found that hearing disorders did not correlate with serum urea, creatinine, sodium or potassium $^{11}$.

the cause of hearing disorder in uremic is still debatable some postulated causes includes Uremic toxins, ototoxins, and axonal uremic neuropathy appear to be likely pathogenic factors, also anemia seems to be an important factor responsible for hearing disorders in patients with end-stage renal failure ${ }^{14}$

Severe patient injury was associated with exposure to aged cellulose acetate membranes of dialyzers, allowing cellulose acetate degradation products to enter the blood. Clinicians should be aware that aged cellulose acetate membranes may cause severe adverse reactions $^{15}$.

On the other hand, the chronic effects of attacks of hemolytic crisis in sickle cell disease patients has also been studied, showing acute hearing loss with the acute attack, especially in the higher frequencies, followed by amelioration of 
the condition, with a cumulative effect over the years with repeated attacks of crisis ${ }^{1-4}$. It was hypothesized that the prevalence of sensorineural hearing loss would be lower than those in children with normal hemoglobin due to suspected compromised cochlear function as a result of vaso-occlusive events characteristic of $\mathrm{SCD}^{16}$.SNHL in SCD patients is mainly due to A high erythrocyte aggregability and low deformability causing obstruction of small blood vesseles ${ }^{17}$.

In some patients with sickle cell disease, an enhanced PMN adhesion to vascular endothelium could contribute to the vascular occlusion that characterizes the acute crisis of the disease ${ }^{18}$.

antiendothelial cell antibodies

(AECA) may play a role in immunemediated vasculitis especially in human sudden hearing loss ${ }^{19}$.

The combined effect of a patient being a sickler, and having end stage renal failure needing dialysis has not been widely studied, if studied at all. The idea of our study was to find if the affection of a patient with both conditions would lead to a simple additive effect on hearing or there is a synergistic effect on hearing, comparing the results with those of other groups of patients in the same environment and within the same age group where the study was carried out.

The results showed that in comparing the normal control group (IV) to the sickle cell disease group patients (III), a significant difference was found only in the $4 \mathrm{kHz}$ frequency, this finding agrees with most of the previous studies that demonstrated an affection of hearing in chronic sickle cell patients, but the limitation of affection in our study to the $4 \mathrm{kHz}$ frequency may be due to the amelioration by the high $\mathrm{HbF}$ levels, so only the higher frequencies (most sensitive) were affected.
Also when comparing the patients with chronic renal failure (group II) with the control group (IV), a significant hearing loss was found in all frequencies, agreeing with most previous studies ${ }^{6,7}$.

When comparing our target group (I) with the control group (IV), a significant difference in all hearing thresholds tested was found, and the same highly significant statistical difference in all thresholds was found when comparing them with the sickle cell disease group (III), but interestingly enough no statistical difference in any level was found when they were compared with group (II) patients having renal failure only.

The overall results show that there is no significant affection of hearing thresholds, at least in the $1000-4000 \mathrm{~Hz}$ range between chronic renal failure patients under dialysis between sicklers and non-sicklers, this may be explained by the more severe and permanent metabolic effect of chronic renal failure on hearing that overrides the effect of chronic and repeated sickling on hearing.

The degree of hearing loss was found to correlate with $\mathrm{kt} / \mathrm{v}$ which mean the better the efficiency of dialysis the less the sesorineural deafness this may support the hypothesis of effect of uremic toxins on hearing not the effect of dialysis although there was no correlation with creatinine the responsible toxins is not defined .also hearing loss correlates with the presence of peripheral neuropathy this may indicate that sesorineural hearing loss may be part of generalized neuropathy which happen to the patients of renal failure on haemodialysis. The degree of hearing loss was also found to correlate with s. calcium may be explained by decreasing the threshold of nerve stimulation by hypocalcemia. Prevalence of peripheral neuropathy in dialysis patients was found to increase 
with the duration of dialysis and decrease with more efficient dialysis.

The role of hemoglobin level in the development of sensorineural hearing loss in dialysis patients had been suggested, we found correlation between $\mathrm{Hb}$ level and hearing threshold at higher frequency $(4 \mathrm{kHz})$ whether in dialysis, sickler on dialysis or sickle cell patients not having renal problem. This relation is not found at 1 nor $2 \mathrm{kHz}$. This matches with the conclusion by Shaheen et al. (2000). Acute SNHL had been found in patients used outdated cellulose acetate membrane but the chronic use of cellulose acetate membrane had not been studied. The correlation between $\mathrm{Hb}$ level and SNHL in patients with sickle cell disease without renal disease may be related to the severity of the vascular effects of the disease which is also associated with lower Hb level.

\section{Conclusion}

The SNHL accompanying chronic renal failure is apparently not aggravated if associated with sickle cell disease, and if any effect would be present, it would only be additive, not synergistic. It increases with duration of dialysis, degree of anemia and with the presence of peripheral neuropathy. It can be reduced with more efficient dialysis.

\section{References:}

1. Crawford MR, Gould HJ, Smith WR, and et al.: Prevalence of hearing loss in adults with sickle cell disease. Ear Hear 1991 Oct; 12(5): 349-51.

2. Ajulo SO, Osiname AI, and Myatt HM.J : Sensorineural hearing loss in sickle cell anemia--a United Kingdom study. Laryngol Otol 1993 Sep;107(9):790-4.

3. Ashoor A, and Al-Awamy B.: Sensorineural hearing loss in sickle cell disease patients in SaudiArabia.Trop Geogr Med 1985 Dec;37(4):314-8.

4. Tsibulevskaya G, Oburra H, and Aluoch JR: Sensorineural hearing loss in patients with sickle cell anaemia in Kenya. East Afr Med J $1996 \mathrm{Jul} ; 73(7): 471-3$.

5. Piltcher O, Cigana L, Friedriech J, et al.: Sensorineural hearing loss am -ong sickle cell disease patients from southern Brazil. Am J Otolaryngol 2000 Mar-Apr;21(2):75-9.

6. Gierek T, Markowski J, Kokot F, et al.: [Electrophysiological examina -tions (ABR and DPOAE) of hearing organ in hemodialysed patients suffering from chronic renal failure] Otolaryngol Pol 2002;56(2):189-94.

7. Stavroulaki P, Nikolopoulos TP, Psarommatis I, et al.: Hearing evaluation with distortion-product otoacoustic emissions in young patients undergoing haemodialysis. Clin Otolaryngol 2001 Jun;26(3):235-42.

8. Serbetcioglu MB, Erdogan S, and Sifil A.:Effects of a single session of hemodialysis on hearing abilities. Acta Otolaryngol 2001 Oct;121(7):836-8.

9. Hoffbrand AV, Pettit JE, and Moss PAH. Genetic disorders of Hemoglobin. In; Hoffbrand AV, Pettit JE, and Moss PAH., eds. Essential hematology. UK: Blackwell Science. 2001, pp 71-90.

10. Mendes RC, Mocllin M, Gavazoni FB, Trevizan GL ,et al,:hearing acuity in chronic renal failure. Rev. bras. Otorhino.(2000),pp638-642.

11. Ozturan O, Lam S: The effect ofhemodialysis on hearing using pure-tone audiometry and distortionproduct otoacoustic emissions. ORL,1998,PP306-313. 
12. Nikolopoulos T, Kandiloros D.C., Segas J.V.,et al: Auditory function in young patients with chronic renal failure,

CLIN.

OTOLARY

NGOL.1997,PP222-225.

13. Samir M., Riad. H., Mahgoub M., Awad $Z$,et al : Transient otoacoustic emissions in children with chronic renal failure, CLIN. OTOLARYNGOL. ALLIED SCI 1998,p87-90.

14. Shaheen F.A.., Mansuri N.A, AlShaikh A.M, et al: Reversible uremic deafness Is it correlated with the degree of anemia. ANN.OTOL.RHINOL.LARYNGOL 1997,p391-393.

15. Hutter JC, Kuehnert MJ, Wallis $\mathbf{R R}$, et al.:Acute onset of decreased vision and hearing traced to hemodialysis treatment with aged dialyzers.JAMA (United States), Apr 26 2000, 283(16) p2128-34.
16. Down CR, Stuart and Holbert D: Distortion product otoacoustic emissions in normal-hearing children with homozygous sickle cell disease.j commun disord 2000;p 111-127.

17. Garcia FJ, Sebastian E, Morant A,et al:sudden deafness in patients with sickle cell trait. Acta Otorrino laringol Esp 2002 May;53(5):371-6 .

18. Fadlon E, Vordermeier S, Pearson T, et al: Blood polymorph -onuclear leukocytes from the majority of sickle cell patients in the crisis phase of the disease show enhanced adhesion to vascular endothelium and increased expression of CD64. Blood 1998 Jan 1;91(1):266-74 .

19. Ottayiani F,Cadoni G,Marinelli L,et al: Anti-endothelial autoantibodies in patients with sudden hearing loss. Laryngoscope 1999 Jul;109(7 Pt 1):1084-7. 


\title{
دراسة ضعف السمع العصبى فى مرضى انيميا الحخلايا المنجلية المصابين بالفشل الكلوى ويقومون باجراء استصفاء دموى
}

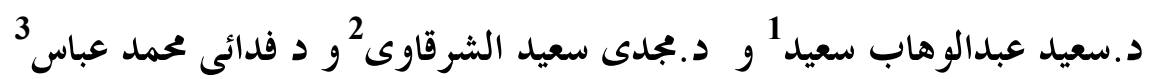

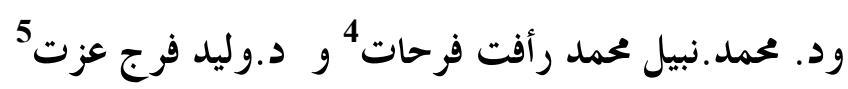

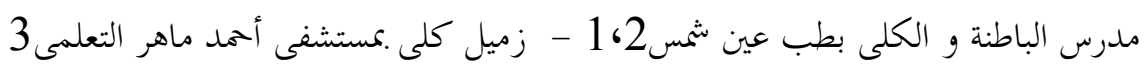

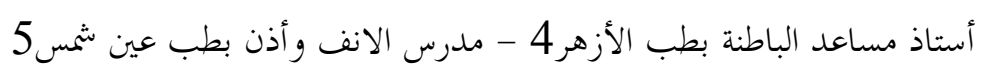

من المعروف ان مرضى الفشل الكلوى يعانون من تدهور بالسمع وقد أجريت دراسات عديدة لمعرفة العلاقة بين

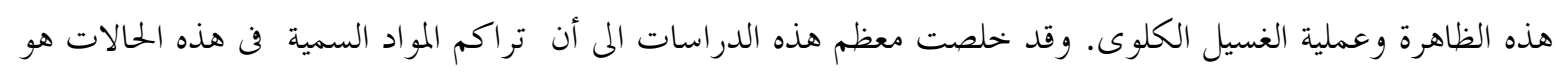

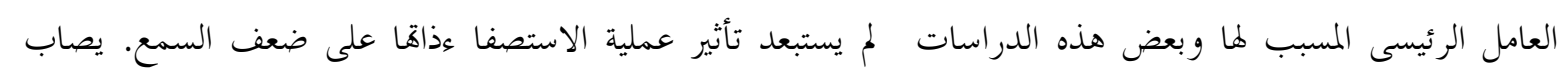

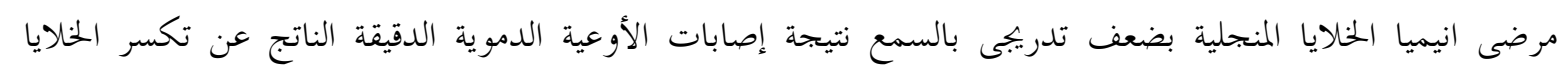

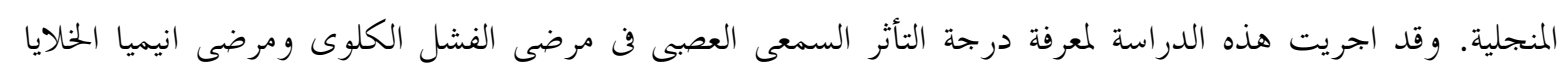

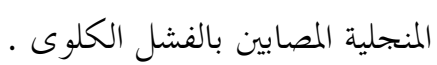

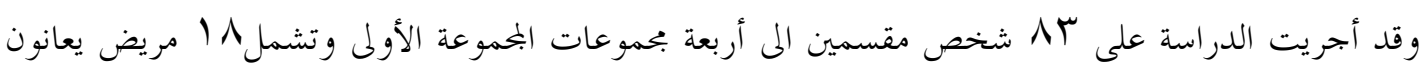

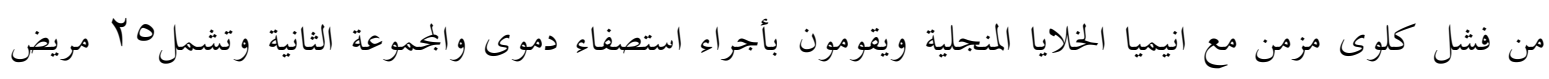

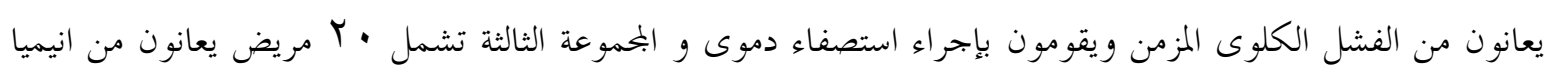

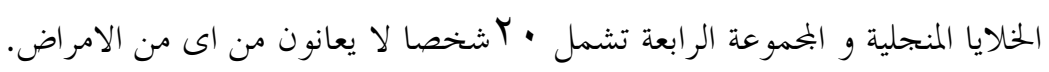

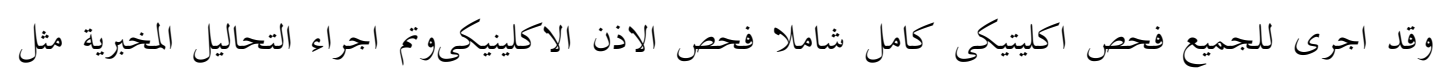

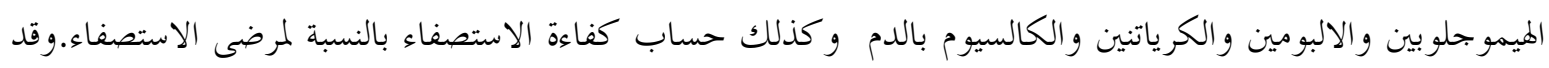

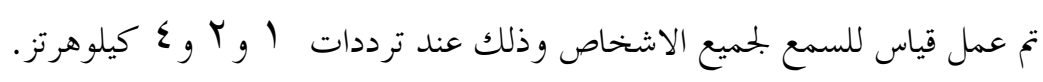

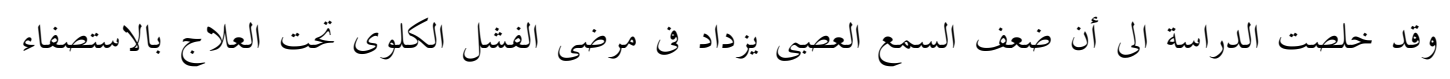

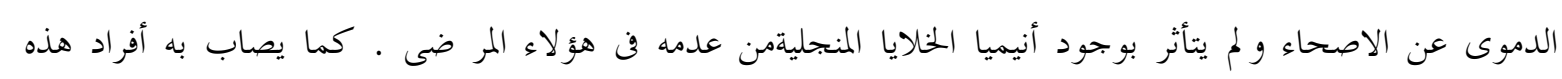

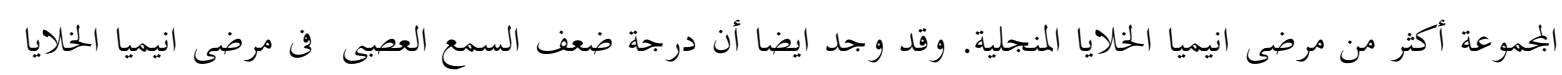

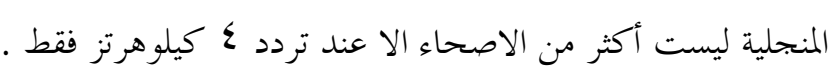

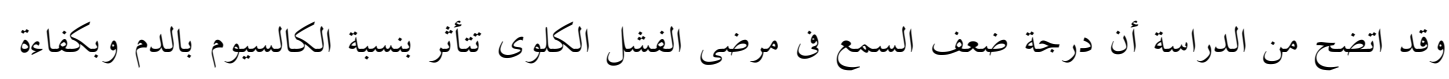

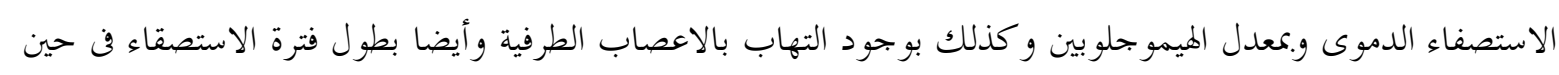

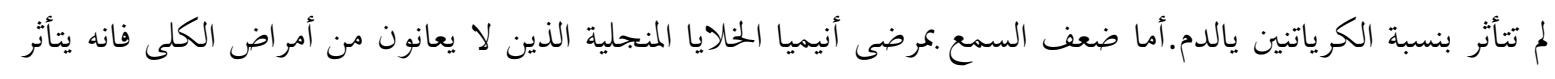

